\title{
An Investigation of Extinguishment by Thermal Agents Using Detailed Chemical Modeling of Opposed Jet Diffusion Flames
}

\author{
WILLIAM M. PITTS ${ }^{1}$, JIANN C. YANG ${ }^{1}$, RODNEY A. BRYANT ${ }^{1}$, and LINDA G. BLEVINS ${ }^{2}$ \\ ${ }^{1}$ National Institute of Standards and Technology \\ Gaithersburg, MD 20899-8662 \\ ${ }^{2}$ Office of Basic Energy Sciences \\ U.S. Department of Energy \\ Washington, DC 20585-1290
}

\begin{abstract}
Detailed chemical kinetic modeling of methane planar opposed-jet laminar diffusion flames burning in air mixed with a variety of thermal agents is used to characterize their effects on maximum flame temperature and extinction behavior. The identification of a well-defined limit temperature allows extinguishing concentrations for buoyancy-dominated methane flames to be predicted. Predicted extinguishing volume fractions are shown to be in good agreement with experimental results for opposed flow methane flames. It is further demonstrated that the calculations provide reliable estimates of relative thermal agent extinguishing effectiveness for both methane coflow flames and liquid-fueled heptane flames burning in a surrounding coflow, even though the required volume fractions of a given agent can differ substantially from those predicted for the opposed flow methane flames. This is the case despite the fact that the extinction mechanisms for the opposed-flow (global flame extinction due to flame cooling) and coflow (blow off of an edge flame stabilized in the local flow field by a reaction kernel) flames are believed to be different. The results of the calculations demonstrate the dependence of extinguishment mechanism on the local flow fields at the flame and the need for thermal agents to lower the temperature of the flame zone to a well defined limit temperature.
\end{abstract}

KEYWORDS: diffusion flames, modeling, suppression, thermal agents

\section{INTRODUCTION}

The manufacture of halons that have been widely used in fire extinguishing systems was banned in 1994 due to their deleterious effect on stratospheric ozone. These agents have been widely employed for fighting fires in nacelles and dry bays on military aircraft. In response to the manufacturing ban, the Department of Defense, under the auspices of its Strategic Environmental Research and Development Program, funded a comprehensive research program to better understand the mechanisms of fire extinguishment and identify effective alternatives for these applications. This multi institutional effort was coordinated by the National Institute of Standards and Technology. An extensive volume summarizing the findings has recently been released. [1]

As part of this coordinated effort to identify suitable halon replacements, we have investigated the feasibility of utilizing thermal agents, defined as those which obtain their effectiveness solely by heat extraction and dilution. [2] Excluded from investigation are species that directly or indirectly disrupt the combustion chemistry such as the halons, which derive much of their effectiveness by the release of bromine atoms that catalytically remove hydrogen atoms in the flame zone.

A great deal is known about the effects of thermal agents on flames. The paper by Sheinson et al. provides a good introduction. [3] There are a number of endothermic physical processes that can extract heat from a gaseous flame zone, thus lowering the temperature and ultimately leading to flame extinguishment. These include simple heating (i.e., heat capacity) of an agent, phase changes such as vaporization of a liquid or sublimation of a solid, endothermic molecular decomposition (which is classified as a physical process as long as the initial agent and its products do not participate in the combustion chemistry), and simple dilution. The flame temperature is also expected to be a function of the thermal diffusivity of a gaseous agent.

This paper describes a detailed chemical-kinetic modeling investigation of methane planar opposed-jet laminar diffusion flames (POJLDFs) burning in air mixed with various known thermal agents that is designed to provide an improved understanding of fire extinguishment by these agents. The results 
discussed here are part of a broader study that has been summarized in an internal report. [2] Another facet of the investigation that utilized idealized surrogate agents to better understand the relative roles of dilution and extraction and the importance of heat extraction location relative to the flame front will be published elsewhere. [4]

\section{DETAILED CHEMICAL KINETIC MODELING}

\section{Flame Configuration and Modeling Approach}

A number of combustion systems have been modeled using detailed chemical kinetic approaches including plug-flow reactors, perfectly stirred reactors, premixed laminar flames, opposed-flow laminar diffusion flames, and coflow laminar diffusion flames. For the present study of fire extinguishment, an opposedflow laminar diffusion flame model was chosen because, for the majority of fires, fuel and air are initially separated and therefore burn as diffusion flames. Most fires are large enough to be turbulent, so a laminar flame model is not strictly correct. However, the most widely used model for turbulent combustion incorporating detailed chemistry is the laminar flamelet concept, which treats the combustion as laminar flame sheets subject to the local strain-rate fields associated with the fire-induced motions of the fluid. [5]

There are three configurations of opposed-flow diffusion flames described in the literature- opposed jet, flow over a porous cylinder, and flow over a porous sphere. For the porous bodies, fuel typically flows from the surface, and the surrounding flow is the oxidizer. The three configurations are related in that a diffusion flame is stabilized near a stagnation region. Numerous papers discuss these types of flames. Two excellent reviews have been provided by Tsuji [6] and Dixon-Lewis [7]. The most common of the three configurations used in the recent past is the POJLDF, which was chosen for the current modeling investigation.

A series of methane POJLDFs have been calculated as functions of the counterflowing fuel and oxidizer velocities at the burner exits (assumed to have equal magnitudes, hereafter referred to as the burner velocity and denoted $U_{b}$ ) and the volume fractions of various thermal agents added to the air flow. Air-side addition is employed since most fire fighting applications of gaseous agents involve mixing with air and subsequent entrainment into the fire. For each concentration of added agent, an extinction condition is identified corresponding to a given exit velocity, $\left(U_{b}\right)_{\text {ext }}$. One focus of this work is the minimum concentration of an agent required to extinguish buoyancy-dominated flames for which local flow conditions are expected to closely mimic those in real-world fires. The extinguishing concentration is expected to correspond to a particular POJLDF extinction condition.

It is well known in the literature that the temperature distribution in a diffusion flame is correlated with its resistance to extinction. A number of representative temperatures have been employed as correlation variables in previous investigations of fire extinguishing agents including the adiabatic flame temperature and the maximum flame temperature. In this investigation the maximum calculated temperature, $T_{\max }$, across the flame is used for this purpose. A hypothesis that has been widely employed in the analysis of flame extinction, particularly with regard to thermal agents, is that extinction occurs when the flame temperature is lowered to a well defined limit temperature. In the current work this hypothesis is tested using calculated values of $T_{\max }$ and $U_{b}$ obtained for conditions where a further small increase in $U_{b}$ results in extinction. These extinction values are denoted $\left(T_{\max }\right)_{\text {ext }}$ and $\left(U_{b}\right)_{\text {ext }}$.

\section{Detailed Chemical Kinetic Model and Mechanism}

The code OPPDIF [8] developed by Sandia National Laboratories and now available commercially from Reaction Design* was used for the calculations. After reviewing the literature, the widely used methane/air mechanism developed with the support of the Gas Research Institute was chosen for the calculations. The version used was GRI-Mech 1.2 that consists of 32 chemical species undergoing 177 reactions. [9] Tests with the later versions 2.11 and 3.0 showed that the results were insensitive to the version used. Thermodynamic and transport data are provided as separate files. The mechanism was generated by starting with appropriate estimates for the rate constants and then optimizing the mechanism to provide the 


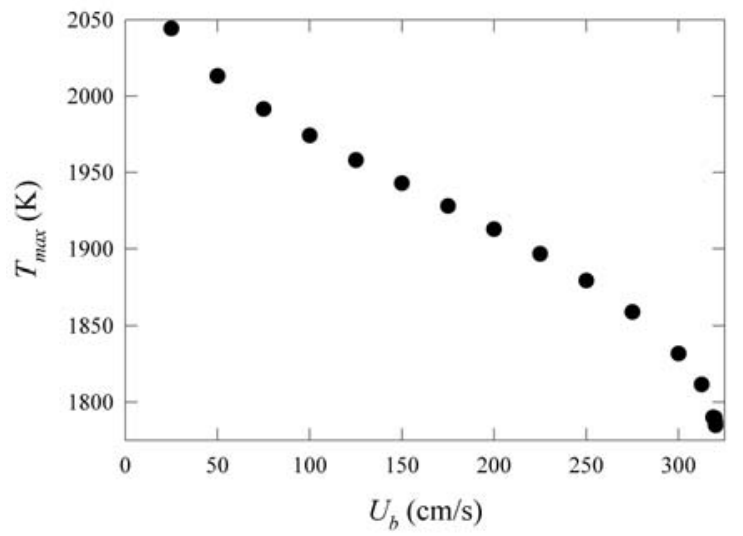

Fig. 1. Calculated values of $T_{\max }$ are plotted against $U_{b}$ for a methane POJLDF burning in air.

best agreement with experimental measurements in such systems as premixed flames, shock tube studies, and flow reactor investigations. [9] Note that the mechanism was not optimized using diffusion flame results.

In order to determine the extinction behavior for a flame, a stable burning solution was first obtained using a relatively low $U_{b}$. The resulting solution was then used as input for a calculation with a higher exit velocity. This process was repeated until a non burning solution was obtained or the calculation failed to converge. These events always occurred when $T_{\max }$ had begun to decrease rapidly, indicating the flame was near its extinction point. By approaching $\left(U_{b}\right)_{\text {ext }}$ in small increments, it was possible to calculate the extinction point to within a step size of $0.01 \mathrm{~cm} / \mathrm{s}$. Continuation methods are often employed to determine extinction conditions. [10] The above approach, which is believed to be equally accurate, was adopted because continuation methods were not implemented in the version of OPPDIF that was used.

The effects of radiative heat losses are not considered in the calculations. Detailed chemical-kinetic modeling studies that included radiative heat loss terms have shown that while flame temperatures are lowered, the effects are relatively small for diffusion flames near extinguishment. [11] Thus while neglect of radiation is expected to introduce differences between calculated and experimental values, it should not invalidate conclusions concerning extinction and extinguishment based on the calculations. A more thorough discussion of this point is included in [2]

\section{MODELING RESULTS AND DISCUSSION}

\section{Methane POJLDF in Air}

Figure 1 shows a plot of $T_{\max }$ versus $U_{b}$ calculated for a methane/air POJLDF. Air is assumed to be composed of $78.1 \%$ nitrogen, $21.0 \%$ oxygen, and $0.9 \%$ argon by volume. As expected, $T_{\max }$ decreases with increasing $U_{b}$. Extinction is calculated to occur for $\left(U_{b}\right)_{\text {ext }}=320 \mathrm{~cm} / \mathrm{s}$ with $\left(T_{\max }\right)_{\text {ext }}=1785 \mathrm{~K}$.

A number of parameters have been used in the literature to characterize the effects of varying exit velocities on POJLDFs. One of these is the maximum value of the velocity gradient element, $a_{o}$, observed on the oxidizer side outside of the boundary layer with $a$ defined as

$a=\frac{\partial u}{\partial z}$,

where $z$ and $u$ are the direction and velocity component normal to the flame sheet. The calculated value of $\left|a_{o}\right|$ for the methane flame at extinction is $509 \mathrm{~s}^{-1}$, which is roughly $25 \%$ higher than measured experimentally. $[12,13,14]$ Tanoff et al. have shown that calculated values of $a_{o}$ are dependent on the detailed mechanism used. [15] In their work GRI-Mech also overpredicted $a_{o}$. 


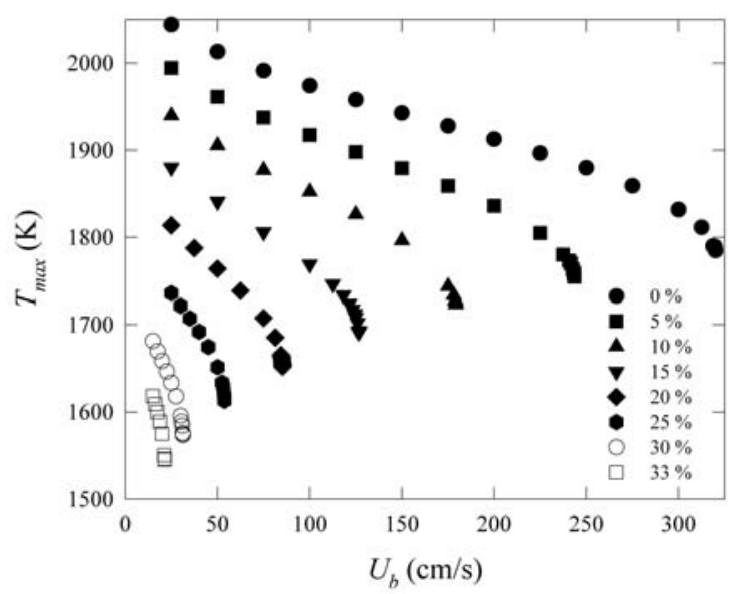

Fig. 2. Values of $T_{\max }$ are plotted as a function of $U_{b}$ for methane POJLDFs burning in air mixed with indicated percentages of nitrogen.

\section{Methane POJLDF in Air/Nitrogen Mixtures}

We have identified only a limited number of experimental measurements of extinguishing concentrations for methane flames burning in air diluted with thermal agents. Most are for nitrogen, and the findings for this agent are summarized in the following. Simmons and Wolfhard [16], Ishizuka and Tsuji [17], and Puri and Sheshadri [18] reported extinguishing volume fractions of $0.338,0.319$, and 0.286 , respectively, for various types of opposed-flow flames. In an as yet unpublished work, Pitts et al. [2] measured a nitrogen extinguishing concentration of 0.332 for a Tsuji-type opposed flow burner included in an especially

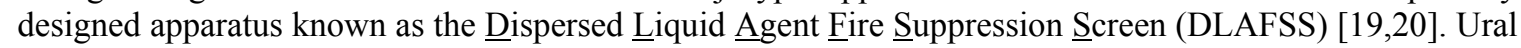
reported an extinguishing nitrogen volume fraction of 0.271 for a coflowing methane diffusion flame in a cup burner apparatus. [21] Takahashi et al. later reported a similar value of 0.26 for an independent cup burner measurement. [22] In their unpublished work [2], Pitts et al. observed an extinguishing nitrogen volume fraction of 0.218 for a coflow methane diffusion flame burning on a Santoro burner [23].

The results summarized above indicate that nitrogen extinguishment concentration measurements for methane flames burning on opposed-flow burners yield higher values than those for coflowing burners. Takahashi et al. noted this difference and attributed it to changes in extinguishment mechanism for the two types of flames. [22] They argue that extinguishment of opposed flow flames occurs when global extinction of combustion reactions takes place. In contrast, their modeling indicates that coflowing flames first lift off the burner with increasing agent concentration in the air coflow. When lifted, the flame is stabilized by a propagating reaction kernel that anchors the flame base in the local flow field generated by the fuel and oxidizer flows. As the agent concentration is increased further, the propagation velocity of the flame kernel is reduced to a point where it can no longer maintain the flame in the flow field, and the flame is suddenly swept downstream and blows off. Since the current modeling involves counter-flow flames, it is most appropriate to compare the results with experimental findings for this type of flame. For this purpose we have chosen a nitrogen extinguishing volume fraction of 0.33 as being representative of the experimental findings for the opposed-flow flames.

A series of calculations was performed for methane POJLDFs reacting with air containing various percentages of added nitrogen. Figure 2 shows the results. While the individual curves of $T_{\max }$ versus $U_{b}$ have similar shapes to that for the methane/air flame shown in Fig. 1, the curves move to left and downward as the percentage of added nitrogen increases. The plots of $T_{\max }$ versus $U_{b}$ become steeper with increasing nitrogen concentration. As a result of these shifts, values of $\left(U_{b}\right)_{\text {ext }}$ and $\left(T_{\max }\right)_{\text {ext }}$ decrease with increasing nitrogen concentration.

As stated earlier, the nominal experimental extinguishing volume fraction of nitrogen was chosen to be 0.33 . The value of $\left(T_{\max }\right)_{\text {ext }}$ for this nitrogen concentration is $1545 \mathrm{~K}$, which can be compared with $\left(T_{\max }\right)_{\text {ext }}$ $=1785 \mathrm{~K}$ calculated for methane burning in air. The value of $\left(T_{\max }\right)_{\text {ext }}$ is close to the experimental value of $1483 \mathrm{~K}$ reported by Ishizuka and Tsuji for an opposed-flow flame of methane and air mixed with nitrogen 
just prior to extinguishment. [17] The agreement is probably better than indicated since the experimental thermocouple measurements were not corrected for radiative heat losses. The calculated $\left(T_{\max }\right)_{\text {ext }}$ should also be overestimated slightly due to neglect of radiative heat losses. Both the calculated and experimental estimates for $\left(T_{\max }\right)_{\text {ext }}$ are similar to others reported in the literature. For example, Sheinson et al. indicate that hydrocarbon combustion is not sustainable when $T_{\max }$ drops below $1600 \mathrm{~K}$. [3] Babb et al. reported radiation-corrected thermocouple temperature measurements in heptane flames near their extinguishment points in air diluted with $\mathrm{N}_{2}$ and $\mathrm{CO}_{2}$ [24]. For both thermal agents, $\left(T_{\max }\right)_{\text {ext }}$ values were close to $1500 \mathrm{~K}$. Measurements with propane yielded $\left(T_{\max }\right)_{\text {ext }}$ of $1600 \mathrm{~K}$ and $1700 \mathrm{~K}$ for added $\mathrm{N}_{2}$ and $\mathrm{CO}_{2}$, respectively.

The findings of Takahashi et al. with regard to flame temperatures are particularly interesting. [22] Their calculations, which include a model for radiative heat losses, for coflow methane flames burning in air mixed with argon, helium, nitrogen, and carbon dioxide show that maximum temperatures inside the reaction kernel remain roughly constant at $\approx 1500 \mathrm{~K}$ as the concentration of thermal agents increases. Interestingly, values of $T_{\max }$ for the diffusion flames stabilized downstream of the reaction kernel fall with increasing concentration, reaching a roughly common value of $\approx 1700 \mathrm{~K}$ for all of the agents just prior to extinguishment. The observation of the nearly constant flame kernel temperature is consistent with the conclusion of Takahashi et al. that the stabilization mechanism of lifted coflowing diffusion flame involves the propagation of the reaction kernel in the local flow field and does not require the kernel temperature to fall to a well defined limit temperature. The fact that calculated $T_{\max }$ in the downstream diffusion flame when blow off occurs are much higher than values of $\left(T_{\max }\right)_{\text {ext }}$ calculated in this study as well as those estimated from experimental studies provides additional support for the conclusion that global extinction of combustion chemistry is not responsible for extinguishment of this type of coflowing diffusion flame.

For the extinguishing concentration of nitrogen, $\left(U_{b}\right)_{\text {ext }}$ is calculated to be $21.4 \mathrm{~cm} / \mathrm{s}$. The corresponding value of $\left|a_{o}\right|$ is $27.0 \mathrm{~s}^{-1}$. An important question concerning the extinction of diffusion flames is: what strain rate is appropriate to use when determining an extinguishing concentration? The only literature discussions of this point identified were presented by Hamins et al. [25] and Saso et al. [26] These authors compared extinguishing concentrations for a variety of agents determined with cup burners fueled with heptane $[25,26]$ and ethanol [26] with corresponding results for counterflow flames. The counterflow measurements were made over a range of exit velocities characterized in terms of global strain rates, $a_{g}$. When the agent concentrations were comparable to those which induced extinguishment in the cup burner, $a_{g}$ values reported by Hamins et al. were roughly $50 \mathrm{~s}^{-1}$, while Saso et al. reported $a_{g}$ values of $.30 \mathrm{~s}^{-1}$. Due to use of different boundary conditions and fuels between the current investigation and those of Hamins et al. and Saso et al., as well as the use of different definitions for the characteristic strain rates, absolute quantitative comparisons are not appropriate. However, it is clear that the characteristic strain rates are of comparable magnitude. It is important to note that the characteristic strain rates appropriate for characterizing extinguishing conditions are much lower than typically used for experimental and modeling investigations of opposed-flow diffusion flames.

It is interesting to speculate why flames subject to Earth's gravity apparently cannot be sustained below a well defined characteristic strain rate. The most likely reason is that buoyancy effects place a limit on the lowest characteristic strain rates present in the flame. Buoyancy always accelerates hot combustion gases relative to the cold oxidizer, with the result that flame surfaces are subject to nonzero strain rates. The results of Hamins et al. [25] and Saso et al. [26], along with the current findings, suggest this strain rate limit is on the order of a few tens of inverse seconds.

\section{Methane POJLDF in Argon “Air”/Argon Mixtures}

As already noted, no additional measurements of extinguishing concentrations for other thermal agents added to counterflow methane/air diffusion flames were identified in the literature. However, Ishizuka and Tsuji did report measurements for methane burning in an artificial "air" consisting of $21 \%$ oxygen and 79 $\%$ argon [17]. This "air" was diluted with argon until extinguishment occurred. The extinguishing volume fraction for added argon was 0.543 . $\left(T_{\max }\right)_{\text {ext }}$ at extinguishment was measured to be $1443 \mathrm{~K}$, or roughly 40 $\mathrm{K}$ less than for burning in standard air diluted with nitrogen.

A series of calculations for methane POJLDFs burning in argon "air" diluted with argon were carried out in the present work. Figure 3 shows values of $T_{\max }$ versus $U_{b}$ determined for flames with indicated percentages of added argon. Comparison with Fig. 2 shows that replacing nitrogen with argon has a 


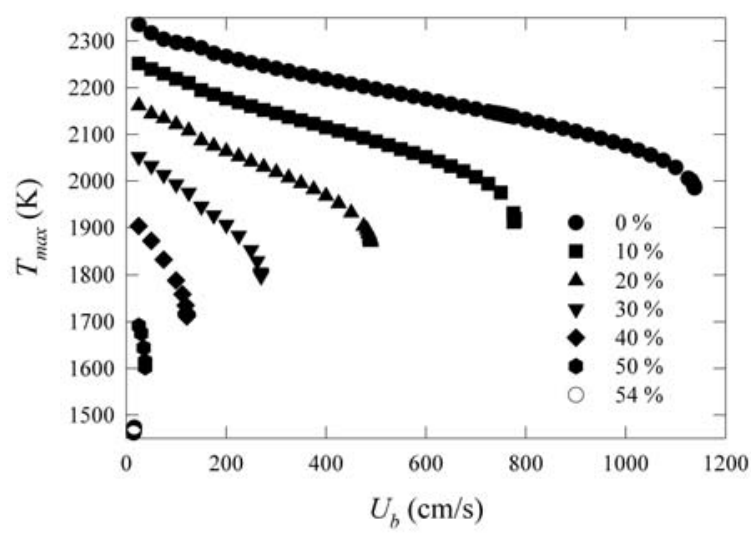

Fig. 3. Values of $T_{\max }$ are plotted as a function of $U_{b}$ for methane POJLDFs burning in argon "air" mixed with indicated percentages of argon.

dramatic effect on the flame structure. First, $T_{\max }$ values are considerably higher for given added argon concentrations and $U_{b}$ for the argon "air". For instance, with no added agent values of $\left(U_{b}\right)_{e x t}=320 \mathrm{~cm} / \mathrm{s}$ and $\left(T_{\max }\right)_{e x t}=1785 \mathrm{~K}$ and $\left(U_{b}\right)_{e x t}=1138 \mathrm{~cm} / \mathrm{s}$ and $\left(T_{\max }\right)_{e x t}=1987 \mathrm{~K}$ are calculated for air and argon "air," respectively. These differences are primarily due to the lower heat capacity of argon as compared to nitrogen. As a result of the increase in temperature, much higher flow velocities are necessary to lower $T_{\max }$ to the point where flame extinction takes place. For the same reason, higher concentrations of argon must be added to achieve extinguishment than in the nitrogen case. A flame burning in argon "air" with 50 $\%$ added argon is calculated to undergo extinction with $\left(T_{\max }\right)_{\text {ext }}=1610 \mathrm{~K}$ and $\left(U_{b}\right)_{\text {ext }}=37.8 \mathrm{~cm} / \mathrm{s}$. The corresponding results for $54 \%$ added argon, the experimental extinguishing volume fraction, are $1473 \mathrm{~K}$ and $15.9 \mathrm{~cm} / \mathrm{s}$. These values are both slightly smaller than found for the methane/air flame diluted with nitrogen, $1545 \mathrm{~K}$ and $21.4 \mathrm{~cm} / \mathrm{s}$, respectively. However, they are remarkably close when one recalls that the use of argon instead of nitrogen should result in a significantly different flame structure due to differences in heat capacity and thermal diffusivity. In fact, if one simply assumes that extinguishment occurs for the same $T_{\max }$, i.e., $1550 \mathrm{~K}$, as for the nitrogen-diluted air flame, the estimate for the required concentration of added argon is $52 \%$. This is only $4 \%$ less than the experimental value. Thus, assuming that flame extinguishment occurs for the agent volume fraction necessary to reduce $T_{\max }$ at extinction to $1550 \mathrm{~K}$ should provide an excellent estimate for the volume fraction of an arbitrary thermal agent required to extinguish a methane flame.

\section{Methane POJLDFs in Air Mixed with Argon, Helium, Nitrogen, Carbon Dioxide, and Water Vapor}

Based on the above encouraging results for predicting extinguishing concentrations, the POJLDF calculations were extended to estimate extinguishing concentrations for methane burning in air mixed with argon, helium, carbon dioxide and water. Water is assumed to be a gas even though at room temperature the required concentrations in air correspond to supersaturated conditions. Each of these gases is expected to act primarily as a thermal agent. The resulting plots (not shown) of $T_{\max }$ versus $U_{b}$ exhibit trends similar to those shown in Fig. 2 and Fig. 3. Estimates of extinguishing concentrations determined assuming $\left(T_{\max }\right)_{\text {ext }}=1550 \mathrm{~K}$ are tabulated in Table 1.

As discussed above, the only experimental literature values of extinguishing concentrations for thermal agents added to air we have identified for methane opposed flow diffusion flames are for nitrogen. In addition to the nitrogen measurements mentioned above, reference [2] includes extinguishment measurements for a methane flame in the DLAFSS for the thermal agents argon and carbon dioxide. These are also included in Table 1. Note that an experimental value reported for helium is not included because it is believed that it was corrupted by an experimental artifact. [2] The agreement between the experimental and calculated values is generally good. 
Table 1. Calculated and experimental extinguishing volume fractions for thermal agents added to the air sides of methane opposed-flow flames.

\begin{tabular}{|c|c|c|}
\hline Thermal Agent & $\begin{array}{c}\text { OPPDIF } \\
\text { Calculations }\end{array}$ & $\begin{array}{c}\text { Experimental DLAFSS } \\
\text { Measurements [2] }\end{array}$ \\
\hline argon & 0.43 & $0.468 \pm 0.002$ \\
\hline helium & 0.33 & -- \\
\hline nitrogen & 0.33 & $0.332 \pm 0.004$ \\
\hline carbon dioxide & 0.22 & $0.240 \pm 0.003$ \\
\hline water vapor & 0.28 & -- \\
\hline
\end{tabular}

Table 2. Experimental extinguishing volume fractions for thermal agents added to the air sides of methane coflow diffusion flames.

\begin{tabular}{|c|c|c|c|}
\hline Thermal Agent & Santoro Burner [2] & Cup Burner [21] & Cup Burner [22] \\
\hline argon & $0.290 \pm 0.004$ & -- & $0.373 \pm 0.015$ \\
\hline helium & $0.200 \pm 0.004$ & -- & $0.267 \pm 0.011$ \\
\hline nitrogen & $0.202 \pm 0.006$ & 0.271 & $0.259 \pm 0.010$ \\
\hline carbon dioxide & $0.120 \pm 0.001$ & -- & $0.157 \pm 0.006$ \\
\hline
\end{tabular}

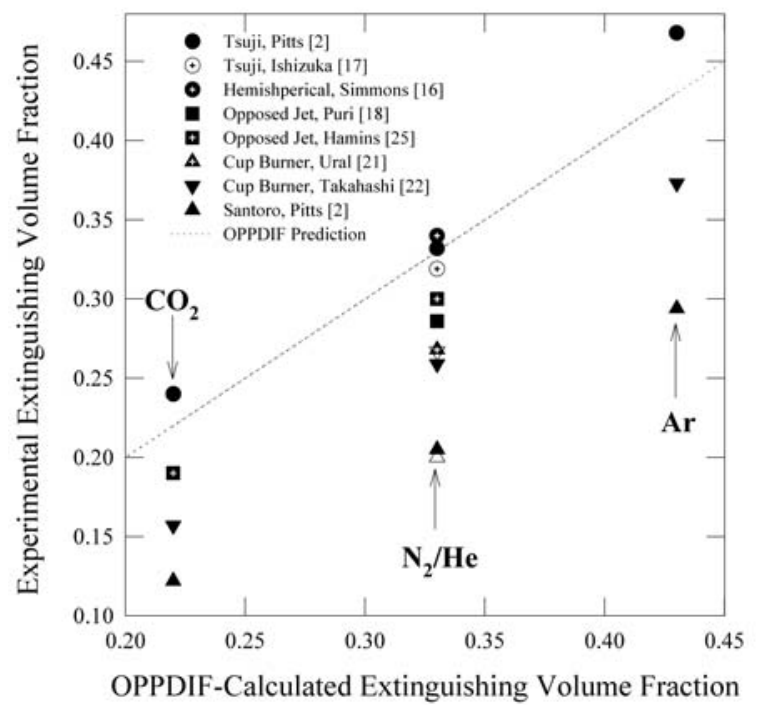

Fig. 4. Values of experimental thermal agent extinguishing concentrations for opposed-flow and coflow methane diffusion flames are plotted against values determined from OPPDIF modeling and assuming $\left(T_{\max }\right)_{\text {ext }}=1550 \mathrm{~K}$. Open symbols are used for helium results.

\section{Comparison of Predicted Thermal Agent Extinguishing Volume Fractions for Methane POJLDFs with Experimental Results for Opposed-Flow and Coflow Methane Flames}

Experimental extinguishing concentrations for methane burning on the Santoro burning are available for argon, helium, nitrogen, and carbon dioxide. [2]. These are collected in Table 2 along with results by Ural [21] and Takahashi et al. [22] for cup burners. Extinguishing concentrations for the Santoro burner are smaller than those for the cup burners. This is likely due to the different fuel/oxidizer velocity ratios used in the two types of burners. The fuel velocities were much lower than the oxidizer flow velocities in the cup burner experiments (fuel velocities ranging from $\approx 0.3 \mathrm{~cm} / \mathrm{s}$ to $\approx 2.7 \mathrm{~cm} / \mathrm{s}$ versus oxidizer velocities of $\approx 9 \mathrm{~cm} / \mathrm{s}$ to $\approx 21 \mathrm{~cm} / \mathrm{s}$ [21]; fuel velocity of $0.92 \mathrm{~cm} / \mathrm{s}$ versus oxidizer velocities ranging from $3 \mathrm{~cm} / \mathrm{s}$ to 15 $\mathrm{cm} / \mathrm{s}$ [22]) while the velocities were matched at $7 \mathrm{~cm} / \mathrm{s}$ for the Santoro burner [2].

Figure 4 shows experimental extinguishing concentrations versus OPPDIF-calculated values for methane flames burning on opposed-flow and coflow burners in air mixed with argon, helium, nitrogen, and carbon 
Table 3. OPPDIFF-predicted thermal agent extinguishing volume fractions for methane flames are compared with cup burner measurements for heptane flames.

\begin{tabular}{|c|c|c|c|c|c|c|c|}
\hline $\begin{array}{c}\text { Thermal } \\
\text { Agent }\end{array}$ & $\begin{array}{c}\text { OPPDIF } \\
\text { Results }\end{array}$ & $\begin{array}{c}\text { Hirst } \\
{[\mathbf{3 1}]}\end{array}$ & $\begin{array}{c}\text { Sheinson } \\
{[\mathbf{3}]}\end{array}$ & $\begin{array}{c}\text { Babb } \\
{[\mathbf{2 4}]}\end{array}$ & $\begin{array}{c}\text { Hamins } \\
{[\mathbf{2 8}]}\end{array}$ & $\begin{array}{c}\text { Moore } \\
{[\mathbf{2 9}]}\end{array}$ & $\begin{array}{c}\text { Saito } \\
{[\mathbf{3 0 ]}}\end{array}$ \\
\hline Nitrogen & 0.33 & 0.302 & 0.30 & 0.33 & 0.32 & 0.30 & 0.336 \\
\hline Argon & 0.43 & - & 0.41 & - & 0.41 & 0.38 & 0.433 \\
\hline Helium & 0.33 & - & 0.32 & - & 0.31 & - & - \\
\hline $\begin{array}{c}\text { carbon } \\
\text { dioxide }\end{array}$ & 0.22 & 0.205 & 0.21 & 0.20 & 0.23 & 0.20 & 0.220 \\
\hline Water & 0.28 & - & - & - & - & - & - \\
\hline
\end{tabular}

dioxide. This figure highlights the differences in the amount of agent required to extinguish opposed flow and coflow methane flames. It is also clear that much less of a given agent is required to extinguish the Santoro coflow burner than is required for the cup burners. Even though there are large differences in the amounts of thermal agent required to extinguish a particular type of burner, the variations in relative effectiveness for the agents are very similar for all of the burners. This is evident by comparing the slope of the line corresponding to the OPPDIF results with the measurements for a given type of burner.

The differences in the extinguishing concentrations of helium and argon seen in Table 2 and Fig. 4 are interesting since both are monatomic gases and have identical molar heat capacities. The difference is clear in both calculated and experimental values. For all of the burners helium is roughly as effective as nitrogen, while considerably higher argon concentrations are required for extinguishment. The higher efficiency for helium means that at least one other parameter, in addition to heat capacity, is important for determining extinguishing efficiency. A related observation was reported by Coward and Hartwell for the inerting of premixed flames that was attributed to the much higher thermal conductivity of helium, which leads to the heat generated by combustion being distributed over a larger volume, thereby lowering the temperature and weakening the flame. [27] The same explanation is likely valid for diffusion flames. Sheinson et al. [3] and Takahashi et al. [22] reached the same conclusion.

\section{Comparison of Predicted Thermal Agent Extinguishing Volume Fractions for Methane POJLDFs with Experimental Results for Heptane Cup Burner Flames}

The cup burner was originally designed to investigate the extinguishment of liquid-fueled fires. The most common fuel used has been heptane. Measurements of extinguishing concentrations of thermal agents for heptane flames have been reported by numerous groups [3, 24, 28, 29, 30, 31]. Results are summarized in Table 3. Values from the current calculations for the methane POJLDF are included for reference. Even though the burner configurations and fuels are different, the OPPDIF results fall close to the experimental measurements. The maximum difference between values calculated for methane and the experimental results for heptane is $12 \%$, with the vast majority being less than $10 \%$. Overall, the cup burner measurements tend to be somewhat lower than for the counter-flow methane flame. It is likely that the agreement is serendipitous, with burner and fuel effects cancelling. Nonetheless, the agreement provides an opportunity to assess the effectiveness of OPPDIF modeling in capturing the relative effectiveness of thermal agents for coflowing diffusion flames.

Figure 5 shows the experimental extinguishing volume fractions for heptane included in Table 3 plotted against the corresponding results calculated for the methane POJLDF. Some systematic variations are evident in the cup burner results, but it is clear that the OPPDIF calculations fall very near the experimental findings. The calculations have done an excellent job of capturing the relative effectiveness of the thermal agents, including once again the similar effectiveness of helium and nitrogen. This is the case even though the specific extinguishment mechanisms for the two flames are quite different. This suggests that global extinction of a flame (opposed-flow flames) and the blow off of a reaction kernel-stabilized edge flame (coflowing flames) are affected by gaseous thermal agents and their three mechanisms of action (dilution, heat extraction, and thermal diffusion) in the same way. 


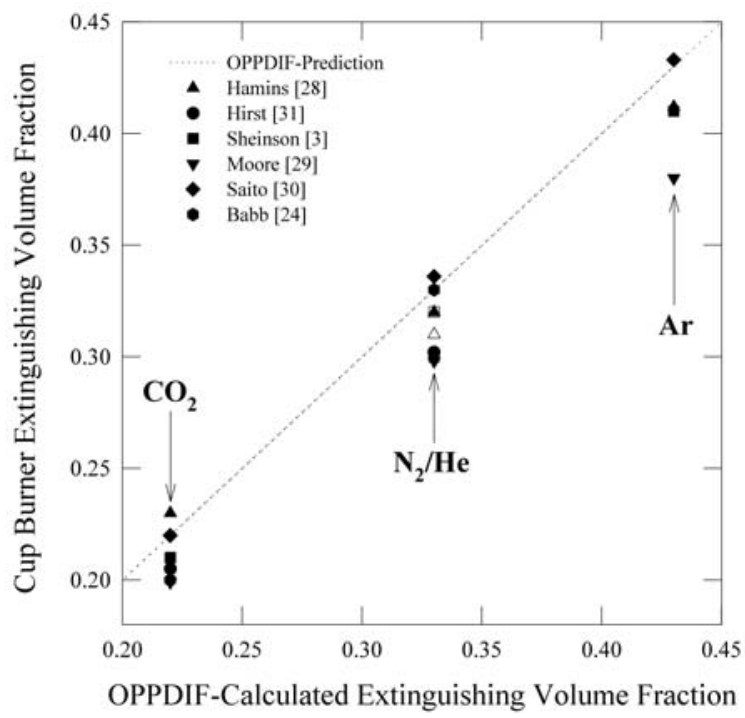

Fig. 5. Cup burner extinguishing volume fractions for heptane are plotted against corresponding calculated results for methane POJLDFs. Open symbols are used for helium results.

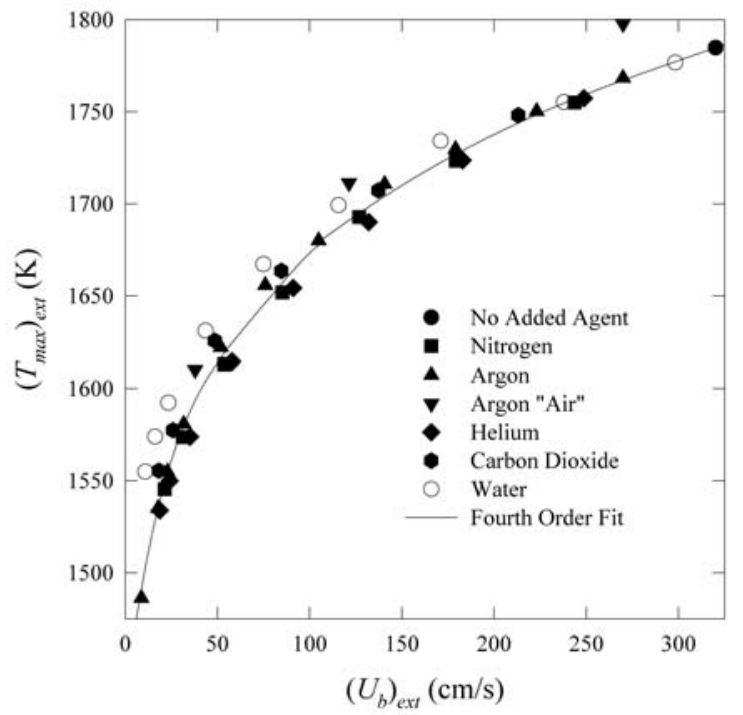

Fig. 6. Values of $\left(T_{\max }\right)_{e x t}$ are plotted against $\left(U_{b}\right)_{\text {ext }}$ for methane POJLDFs burning in air mixed with the indicated thermal agents and argon "air" mixed with argon.

\section{VALIDITY OF THE EXTINGUISHING LIMIT FLAME TEMPERATURE HYPOTHESIS}

The success of the combination of OPPDIF calculations with the concept of a well defined extinguishming temperature provides strong evidence that the limit temperature is physically meaningful. Additional evidence for this is obtained by plotting values of $\left(T_{\max }\right)_{e x t}$ versus values of $\left(U_{b}\right)_{\text {ext }}$ for argon, helium, nitrogen, and carbon dioxide flames at extinction conditions. The results collapse to a single well defined curve as evident in Fig. 6. The solid line included in the figure is the result of fits of the data to two piecewise fourth-order polynomials on either side of $105 \mathrm{~cm} / \mathrm{s}$ for the these four agents. It is remarkable how well the data collapse when it is recognized how widely the agent concentrations vary for given values of $\left(U_{b}\right)_{\text {ext }}$. This finding suggests that the limit flame temperature in POJLDFs is determined primarily by the local velocity field, which is related to local values of strain and scalar dissipation rates. 
The results for argon "air" mixed with argon discussed earlier are included in Fig. 6. For high $\left(U_{b}\right)_{e x t}$, $\left(T_{\max }\right)_{\text {ext }}$ values lie well above the curve fit. This is to be expected since values of $T_{\max }$ were shown to be considerably higher for methane burning in argon "air" as compared to burning in air. Interestingly, as the values of $\left(U_{b}\right)_{\text {ext }}$ decrease as argon is added to the argon "air," values of $\left(T_{\max }\right)_{\text {ext }}$ move closer to the curve fit. This observation explains the good agreement between the experimental and predicted values of extinguishing volume fraction for argon added to argon "air".

The results for water vapor added to air are also included in Fig. 6. The values generally fall close to the curve fit, but, particularly for smaller $\left(U_{b}\right)_{\text {ext }}$, lie slightly above. This is likely an indication that the addition of water vapor has a small chemical effect on the methane flame chemistry. Such an effect might be anticipated since the water molecule is an active participant in the combustion chemistry and is therefore capable of shifting partial equilibria and modifying individual reaction rates.

In our internal report [2] as well as a manuscript submitted elsewhere for publication [4] detailed chemical kinetic modeling combined with idealized surrogate thermal agents is used to investigate mechanisms of extinction in more detail. By varying the properties of the surrogate, these agents were designed to cover an extremely wide range of extinguishing concentrations. When values of $\left(T_{\max }\right)_{\text {ext }}$ were plotted versus $\left(U_{b}\right)_{\text {ext }}$ for these purely thermal agents the results collapsed quite well onto the curve fit shown in Fig. 6. Taken together with the findings for actual thermal agents, these results provide powerful and robust support for the use of a well defined limit temperature for understanding and predicting global flame extinguishment of counter-flow diffusion flames.

\section{SUMMARY}

It has been shown that detailed chemical kinetic modeling provides quantitative predictions for the amounts of simple thermal agents required to extinguish methane POJLDFs. The success of the approach indicates that the effectiveness of a thermal agent is determined primarily by its ability to lower the flame temperature and the local strain rates or, equivalently, scalar dissipation rates, generated by the local flow field. The assumption that $\left(T_{\max }\right)_{\text {ext }}=1550 \mathrm{~K}$ provides good quantitative agreement with experiments for the amount of a thermal agent that must be added to air to extinguish methane counter-flow flames. Characteristic strain rates for buoyancy-dominated diffusion flames are on the order of a few tens of inverse seconds. The use of a well defined limit temperature for extinguishment is an integral part of the analysis. The success of the approach along with the collapse of plots of $\left(T_{\max }\right)_{\text {ext }}$ versus $\left(U_{b}\right)_{\text {ext }}$ for a range of thermal agents provides strong support for the existence of a well defined $\left(T_{\max }\right)_{\text {ext }}$ at extinguishment

The amounts of thermal agents required to extinguish coflowing methane diffusion flames were generally lower than those for counter-flow flames. These differences were attributed to a change in the extinguishment mechanism from global quenching of combustion for the counter-flow flames to blow off of stabilized edge flames for the coflow flames. Despite the difference in extinguishing mechanism, the relative effectiveness of the thermal agents is roughly the same for all of the flames considered. This is even true for extinguishment of heptane cup burner flames which were shown to require roughly the same concentrations as the methane counter-flow flames. This suggests that the ability of the flame kernel to act as an anchor in the velocity field generated by the coflow flame is degraded by heat losses from the kernel in much the same way as temperature is reduced in the counter-flow flames even though the maximum kernel temperature remains roughly constant with increasing agent concentration. The similarity of maximum temperatures in the kernel [22] and $\left(T_{\max }\right)_{e x t}$ at extinguishment is consistent with this conclusion.

*Certain commercial equipment, instruments, or material are identified in this paper in order to adequately specify the experimental procedure. Such identification does not imply recommendation or endorsement by the National Institute of Standards and Technology, nor does it imply that the materials or equipment are necessarily the best available for the purpose.

\section{ACKNOWLEDGMENT}

This research was part of the Department of Defense's Next Generation Program Fire Suppression Technology Program, funded in part by the DoD Strategic Environmental Research and Development Program under Contract W74RDV73243630. 


\section{REFERENCES}

[1] Gann, R.G., Ed., "Advanced Technology for Fire Suppression in Aircraft. Final Report of the Next Generation Fire Suppression Technology Program," National Institute of Standards and Technology Special Publication NIST SP1069, Gaithersburg, MD, 2007, 1186 p.

[2] Pitts, W.M., Yang, J.C., Bryant, R.A., Huber, M., and Blevins, L.G., "Characterization and Identification of Super-Effective Thermal Fire Extinguishing Agents-Final Report, NGP Project 4C/1/890," National Institute of Standards and Technology Technical Note NIST TN1440, Gaithersburg, MD, 2006, 138 p.

[3] Sheinson, R.S., Penner-Hahn, J.E., and Indritz, D., (1989) The Physical and Chemical Action of Fire Suppressants, Fire Safety Journal 15: 437-450, http://dx.doi.org/10.1016/0379$\underline{7112(89) 90015-5}$

[4] Pitts, W.M., (2009) Improved Understanding of Thermal Agent Fire Suppression Mechanisms from Detailed Kinetic Modeling with Idealized Surrogate Agents, Proceeding of the Combustion Institute 32:, to appear .

[5] Peters, N., (1984) Laminar Diffusion Flamelet Models in Non-Premixed Turbulent Combustion, Progress in Energy and Combustion Science 10: 319-339, http://dx.doi.org/10.1016/0360$\underline{1285(84) 90114-X}$

[6] Tsuji, H., (1982) Counterflow Diffusion Flames, Progress in Energy and Combustion Science 8: 93-119, http://dx.doi.org/10.1016/0360-1285(82)90015-6

[7] Dixon-Lewis, G., "Structure of Laminar Flames," Proceedings of the Combustion Institute 23, 1990, pp. 305-324.

[8] Lutz, A.E., Kee, R.J., Grcar, J.F., and Rupley, F.M., "OPPDIF: A Fortran Program for Computing Opposed-Flow Diffusion Flames," Sandia National Laboratories Report Number SAND96-8243, Livermore, CA, 1996, 39 p., http://dx.doi.org/10.2172/568983

[9] Frenklach, M., Wang, H., Yu, C.-L., Goldenberg, M., Bowman, C.T., Hanson, R.K., Davidson, D.F., Chang, E.J., Smith, G.P., Golden, D.M., Gardiner, W.C., and Lissianski, V., GRI-MECH 1.2, http://www.me.berkeley.edu/gri mech/

[10] Giovangigli, V. and Smooke, M.D., (1987) Extinction of Strained Premixed Laminar Flames with Complex Chemistry, Combustion Science and Technology 53: 23-49, http://dx.doi.org/10.1080/00102208708947017

[11] Maruta, K., Yoshida, M., Guo, H., Ju, Y., and Niioka, T., (1998) Extinction of Low-Stretched Diffusion Flame in Microgravity, Combustion and Flame 112: 181-187, http://dx.doi.org/10.1016/S0010-2180(97)81766-X

[12] Papas, P., Fleming, J.W., and Sheinson, R.S., "Extinction of Non-Premixed Methane- and Propane-Air Counterflow Flames Inhibited with $\mathrm{CF}_{4}, \mathrm{CF}_{3} \mathrm{H}$, and $\mathrm{CF}_{3} \mathrm{Br}$," Proceedings of the Combustion Institute 26, 1996, pp. 1405-1411.

[13] Chelliah, H.K., Law, C.K., Ueda, T., Smooke, M.D., and Williams, F.A., “An Experimental and Theoretical Investigation of the Dilution, Pressure, and Flow-Field Effects on the Extinction Condition of Methane-Air-Nitrogen Diffusion Flames," Proceedings of the Combustion Institute 23, 1990, pp. 503-511.

[14] Du, J. and Axelbaum, R.L., "The Effects of Flame Structure on Extinction of $\mathrm{CH}_{4}-\mathrm{O}_{2}-\mathrm{N}_{2}$ Diffusion Flames," Proceedings of the Combustion Institute 26, 1996, pp. 1137-1142.

[15] Tanoff, M.A., Dobbins, R.R., Smooke, M.D., Burgess, Jr., D.R., Zachariah, M.R., Tsang, W., and Westmoreland, P.R., "C1 and C2 Fluorinated Hydrocarbon Effects on Extinction Characteristics of Methane vs. Air Counterflow Diffusion Flames," Proceedings of the Halon Options Technical Working Conference, 1997, pp. 116-127. 
[16] Simmons, R.F. and Wolfhard, H.G., (1957) Some Limiting Oxygen Concentrations for Diffusion Flames in Air Diluted with Nitrogen, Combustion and Flame 1: 155-161, http://dx.doi.org/10.1016/0010-2180(57)90042-1

[17] Ishizuka, S. and Tsuji, H., "An Experimental Study of Effect of Inert Gases on Extinction of Laminar Diffusion Flames,” Proceedings of Combustion Institute 18, 1981, pp. 695-703.

[18] Puri, I. K. and Seshadri, K., (1986) Extinction of Diffusion Flames Burning Diluted Methane and Diluted Propane in Diluted Air, Combustion and Flame 65: 137-150, http://dx.doi.org/10.1016/0010-2180(86)90015-5

[19] Yang, J.C., Donnelly, M.K., Privé, N.C., and Grosshandler, W.L., (2001) An Apparatus for Screening Fire Suppression Efficiency of Dispersed Liquid Agents, Fire Safety Journal 36: 55-72, http://dx.doi.org/10.1016/S0379-7112(00)00042-4

[20] Yang, J.C., Donnelly, M.K., Privé, N.C., and Grosshandler, W.L., "Dispersed Liquid Agent Fire Suppression Screen Apparatus," National Institute of Standards and Technology Internal Report NISTIR 6319, Gaithersburg, MD, 1999, 94 p.

[21] Ural, E.A., "Measurement of the Extinguishing Concentration of Gaseous Fuels Using the CupBurner Apparatus," Proceedings of the Halon Options Technical Working Conference, 1999, pp. 275-283.

[22] Takahashi, F., Linteris, G.T., and Katta, V.R., "Extinguishment Mechanisms of Coflow Diffusion Flames in a Cup-Burner Apparatus," Proceedings of the Combustion Institute 31, 2007, pp. 27212729, http://dx.doi.org/10.1016/j.proci.2006.08.112

[23] Santoro, R.J., Semerjian, H.G., and Dobbins, R.A., (1983) Soot Particle Measurements in Diffusion Flames, Combustion and Flame 51: 203-218, http://dx.doi.org/10.1016/0010$\underline{2180(83) 90099-8}$

[24] Babb, M., Gollahalli, S.R., and Sliepcevich, C.M., (1999) Extinguishment of Liquid Heptane and Gaseous Propane Diffusion Flames, Journal of Propulsion and Power 15: 260-265.

[25] Hamins, A., Trees, D., Seshadri, K., and Chelliah, H.K, (1994) Extinction of Nonpremixed Flames with Halogenated Fire Suppressants, Combustion and Flame 99: 221-230, http://dx.doi.org/10.1016/0010-2180(94)90125-2

[26] Saso, Y., Saito, N., Liao, C., and Ogawa, Y., (1996) Extinction of Counterfiow Diffusion Flames with Halon Replacements, Fire Safety Journal 26: 303-326, http://dx.doi.org/10.1016/S03797112(96)00020-3.

[27] Coward, H.F. and Hartwell, F.J., (1926) Extinction of Methane Flames by Diluent Gases, Journal of the Chemical Society CXCVII: 1522-1532, http://dx.doi.org/10.1039/jr9262901522

[28] Hamins, A., Gmurczyk, G., Grosshandler, W., Rehwoldt, R.G., Vazquez, I., Cleary, T., Presser, C., and Seshadri, K., “4. Flame Suppression Effectiveness,” in Grosshandler, W.L., Gann, R.G., and Pitts, W.M., Eds., "Evaluation of Alternative In-Flight Fire Suppressants for Full-Scale Testing in Simulated Aircraft Engine Nacelles and Dry Bays", National Institute of Standards and Technology Special Publication SP861, 1994, pp. 345-465.

[29] Moore, T.A., Weitz, C.A., and Tapscott, R.E., Update on NMERI Cup-Burner Test Results, Halon Options Technical Working Conference, 1996, pp. 551-564.

[30] Saito, N., Ogawa, Y., Saso, Y., Liao, C., and Sakei, R., (1996) Flame-Extinguishing Concentrations and Peak Concentrations of $\mathrm{N}_{2}, \mathrm{Ar}, \mathrm{CO}_{2}$ and Their Mixtures for Hydrocarbon Fuels, Fire Safety Journal 27: 185-200, http://dx.doi.org/10.1016/S0379-7112(96)00060-4

[31] Hirst, R. and Booth, K., (1977) Measurement of Flame-Extinguishing Concentrations, Fire Technology 13: 296-315, http://dx.doi.org/10.1007/BF02319727. 